\title{
PRODUÇÃO DE Metarhizium anisopliae EM DIFERENTES ESCALAS E EM BIORREATOR DE BANDEJA
}

\author{
I. C. LOPES $^{1 *}$, F. P. CASCIATORI ${ }^{2}$, J. C. THOMÉO ${ }^{3}$ \\ ${ }^{1}$ Universidade Estadual Paulista, Departamento de Microbiologia \\ ${ }^{2}$ Universidade Estadual Paulista, Departamento de Engenharia e Ciências de Alimentos \\ ${ }^{3}$ Universidade Estadual Paulista, Departamento de Engenharia e Ciências de Alimentos \\ "e-mail: isalops@hotmail.com
}

\begin{abstract}
RESUMO
O objetivo deste trabalho é otimizar a produção de Metarhizium anisopliae através de alterações do substrato e das condições de cultivo e produzi-lo em biorreator de bandeja. Para otimizar as condições de cultivo, foram realizados testes alterando-se o substrato. Inicialmente os substratos arroz tipo 1 e quirera foram submetidos a teste de crescimento em condições de abrigo de luz. Após comparação de produção de conídios nos dois substratos, foram realizados testes em escala maior em embalagens plásticas, utilizando arroz tipo $1 \mathrm{com}$ até $500 \mathrm{~g}$ de substrato. Um biorreator de bandeja, com aeração realizada sobre a camada de substrato, foi projetado e construído e um teste realizado com arroz tipo 1, com camada de $2 \mathrm{~cm}$ de espessura, correspondendo a $1 \mathrm{~kg}$ de substrato. Em todos os ensaios, a resposta observada foi a concentração de conídios. De acordo com os resultados apresentados, a quirera apresentou resultados satisfatórios nos ensaios, podendo ser considerada uma opção viável para utilização industrial devido ao seu baixo custo. O biorreator de bandeja elaborado apresentou bons resultados de produção de conídios em relação a produção em embalagem plástica de maior capacidade com o substrato arroz tipo 1.
\end{abstract}

\section{INTRODUÇÃO}

O uso excessivo de agentes químicos causa efeitos negativos para o complexo biótico de natureza (MOCHI et al., 2005.), afetando os microrganismos, as propriedades do solo e acarretando a predisposição a doenças ou uma redução temporária no crescimento das plantas (ALTMAN e CAMPBELL, 1977).

Na população humana, constantemente exposta a vários defensivos químicos por uma exposição ambiental direta ou indireta pela ingestão de alimentos contaminados
(REFFSTRUP et al., 2010), tem aumentado os riscos de doenças como o câncer (MATTSSON, 2008).

O controle microbiano representa um ramo do controle biológico que trata da utilização racional de bactérias, fungos, vírus e nematoides para o controle de insetos pragas. Apesar do uso desses organismos representar apenas $1 \%$ do mercado total de produtos para proteção de plantas, nos últimos anos um número significativo de pesquisas promoveu o aumento da quantidade de produtos disponíveis e ampliou as perspectivas para o mercado. 
Os fungos foram os primeiros patógenos de insetos utilizados no controle microbiano (ALVES, 1998) e mais de 150 produtos para o controle biológico de insetos pragas feitos a partir de fungos entomopatogênicos já foram comercializados (FARIA e WRAIGHT, 2007).

A ocorrência da entomopatogenicidade (capacidade de produzir doença em insetos) depende de uma cadeia de eventos bioquímicos e mecânicos sincronizados. Primeiro, o conídio (unidade infectiva) adere e germina sobre a cutícula do inseto (ST LEGER et al., 1991), fazendo então a penetração, uma combinação de degradação enzimática e pressão mecânica, onde enzimas hidrolíticas como quitinases, proteases e lipases são produzidas (ST LEGER et al., 1998). Em seguida, as hifas que atravessaram a cutícula do hospedeiro engrossam e se ramificam.

A tecnologia desenvolvida no Brasil permitiu que grandes culturas, como a de cana-de-açúcar e de soja, concentrassem os maiores programas mundiais utilizando patógenos de insetos. Esses programas são responsáveis pelo tratamento biológico de aproximadamente 2,5 milhões de hectares de cana e soja por ano.

O interesse comercial no desenvolvimento de produtos para controle microbiano de insetos teve início em torno de 1950, quando se constatou a possibilidade de manipular microrganismos para causar doenças em insetos pragas sem provocar danos às espécies benéficas.

Os bioinseticidas são vistos hoje como um componente efetivo e de valor nos sistemas de manejo integrado. No Brasil, a produção comercial de bioinseticidas vem crescendo anualmente gerando emprego, renda e impulsionando um segmento estratégico para agregação de valor aos produtos do agronegócio.

No atual cenário do agronegócio brasileiro, o crescimento da agricultura orgânica, aliado às exigências de alimentos isentos de agrotóxicos por parte do mercado consumidor, vêm propulsionando o avanço e desenvolvimento de produtos biológicos para controle de pragas agrícolas. Entre os agentes de biocontrole mais utilizados no mundo, os fungos entomopatogênicos exercem um importante papel em programas de manejo integrado de pragas. Esses fungos são encontrados naturalmente infectando e causando doenças em níveis epizoóticos (grande número de insetos infectados) em populações de artrópodes. $\mathrm{O}$ controle biológico vem atraindo mais adeptos por ser uma opção não poluente, favorável ao equilíbrio biológico, ser duradouro e por aproveitar o potencial biótico do agroecossistema, não ser tóxico para os homens e animais, poder ser aplicado com máquinas convencionais com pequenas adaptações e, principalmente, ter boa relação custo/benefício.

O entomopatógeno Metarhizium anisopliae (Metschnikoff) Sorokin é um fungo deuteromiceto filamentoso, usado inicialmente para o controle do besouro do grão do trigo, Anisoplia austriaca, e do curcúleo da beterraba, Cleonus punctiventris (ROBERTS e ST LEGER, 2004).

No Brasil, este fungo vem sendo utilizado no controle biológico de percevejos das pastagens, gênero Deois (PEREIRA et al., 2008), da cigarrinha da cana-de-açúcar, Mahanarva posticata (ALVES, 1998), da broca da cana-de-açúcar, Diatraea saccharalis, (OLIVEIRA et al., 2008) e carrapatos de impacto na pecuária, como Rhipicephalus (Boophilus) microplus (BEYS DA SILVA et al., 2010).

Sua eficácia no controle biológico depende da aplicação e da quantidade aplicada. O ideal é que seja aplicado à tarde, quando há menos incidência de raios ultravioleta e, preferencialmente, logo após as chuvas. O mínimo recomendado é de dois 
quilos por hectare, podendo ser aplicado até cinco quilos ou mais (TONUS, 1999).

Entre as principais vantagens da utilização do Metarhizium anisopliae no controle biológico de insetos pragas está a facilidade de produção das suas unidades infectivas em escala comercial, facilidade de aplicação em condições de campo, o baixo custo decorrido de sua utilização e, principalmente, o reduzido impacto ambiental.

Metarhizium anisopliae é o fungo mais estudado e produzido em escala comercial no Brasil e seu uso já atingiu mais de um milhão de hectares tratados. Uma das aplicações mais difundidas deste fungo é no controle da cigarrinha (Mahanarva posticata) da cana-deaçúcar. Vários trabalhos continuam sendo conduzidos em condições de laboratório e campo com este fungo, principalmente em virtude da sua ampla variabilidade genética, grande variedade de hospedeiros e facilidade de produção usando substratos artificiais. Para que a produção deste microrganismo seja ampliada em escala comercial, torna-se importante desenvolver métodos eficientes de produção.

No Brasil, este fungo é produzido basicamente por um processo conhecido como fermentação em estado sólido. Neste caso, objetiva-se produzir os propágulos infectivos do fungo, denominado conídios, mediante o uso de substratos sólidos à base de cereais, em geral arroz tipo 1, os quais fornecem condições nutricionais e físicas necessárias ao crescimento do microrganismo, sem a necessidade de aditivos. $O$ conhecimento desse processo de produção do fungo $M$. anisopliae se torna útil e importante para aqueles envolvidos na área de controle microbiano aplicado.

Apesar da importância, grande parte da produção comercial de fungos utiliza técnica artesanal ou semi-industrial, caracterizada pela elevada utilização de mão-de-obra, pequeno ou nenhum índice de automatização do processo, utilização de equipamentos adaptados de outros usos e utilização de meios de cultura preparados com matéria prima bruta ou com processamento mínimo (PEREIRA e ALVES, 1998).

As estruturas mais produzidas e comercializadas de $M$. anisopliae são os conídios, produzidos na superfície de meio de cultura sólido, dentro de diferentes recipientes conforme o objetivo e escala de produção (ALMEIDA; BATISTA FILHO, 2006), sendo $\mathrm{o}$ arroz o substrato mais utilizado para a produção conidial. Isto se deve, provavelmente, à combinação de fatores como balanço nutricional, custo, ampla disponibilidade mundial, características físicas como tamanho e forma do grão, propriedades de hidratação e integridade estrutural mesmo após a colonização pelo fungo (JENKINS et al., 1998).

Um grande número de trabalhos de FES tem sido desenvolvido em escala laboratorial utilizando frascos de vidro ou sacos de polietileno, buscando avaliar a viabilidade de um determinado produto a partir de um binômio substrato-microrganismo específico. Tais estudos são normalmente conduzidos sob condições operacionais controladas, onde as variáveis composição e umidade inicial do substrato e temperatura do sistema são impostas na busca de pontos ótimos de operação. Isso só é possível porque, na escala laboratorial, controlar a temperatura no valor ótimo para o crescimento do microrganismo e para a produção dos bioprodutos de interesse é uma tarefa relativamente fácil. Nesta escala, muitos processos de FES têm-se demonstrado um tanto quanto promissores. No entanto, a transposição destes processos para biorreatores em escala comercial, que contém grande quantidade de substrato, a difícil remoção de calor de leitos de sólidos com baixa quantidade de água implica em um difícil controle de temperatura no interior do biorreator de leito empacotado, e as condições ótimas de operação, via de regra, não são 
possíveis de serem mantidas, devido ao fato de que, nos ensaios em escala de reatores, o substrato inoculado fica sujeito às variações de temperatura decorrentes da atividade microbiana e às variações de umidade resultantes da interação entre a matriz porosa e o ar percolante. Assim, a transposição dos resultados de uma escala para outra não é trivial, normalmente resultando em baixa produtividade do reator (LAURENTINO, 2007).

Desta forma, tem-se que um grande inconveniente da FES em leitos fixos é a dificuldade no controle da temperatura do leito, com possibilidade de ocorrência de superaquecimento do meio, com consequente queda de produtividade do sistema e mesmo a morte dos microrganismos. As temperaturas alcançadas podem estar bem acima da temperatura ótima para os processos, de forma que a acumulação de calor possa ser tão alta que chega a danificar o produto formado e acumulado no leito (MITCHELL et al., 2000). Durante os momentos de pico de produção de calor pelo metabolismo do microrganismo, a temperatura pode chegar a valores de $10{ }^{\circ} \mathrm{C}$ acima da temperatura ótima de crescimento (GHILDYAL et al., 1994).

De modo geral, a ampliação de escala em FES não segue técnica pré-definida, sendo feita de acordo com as necessidades do trinômio microrganismo-substrato-produto, como se vê em trabalhos da literatura (ABDAESHAHIAN et al., 2010; CUNHA et al., 2009; VIRTANEN et al., 2008a, 2008b) e baseada na experiência do projetista.

De acordo com Zhao et al. (2008), a ampliação de escala em FES é um desafio, pois as condições de aeração, umidade e temperatura mudam drasticamente da menor para a maior escala. Para Cunha et al. (2009), as condições ótimas obtidas na escala de frascos para crescimento microbiano $\mathrm{e}$ metabolização de produtos raramente são reproduzidas em escala ampliada. Na FES, a transferência de calor é o principal fator limitante, devido à baixa condutividade térmica dos materiais orgânicos e às baixas vazões de ar, de forma que a remoção do calor metabólico gerado é problemática.

\section{OBJETIVO}

O objetivo geral do presente trabalho é otimizar a produção de conídios do fungo Metarhizium anisopliae, aumentar a escala da produção em embalagens plásticas de grande capacidade, como atualmente realizado em biofábricas e cultivar o fungo em biorreatores de bandeja e avaliar sua operacionalidade para a produção em larga escala

\section{MATERIAIS E MÉTODOS}

Os ensaios foram realizados no Laboratório de Engenharia de Processos e Biorreatores do Departamento de Engenharia e Tecnologia de Alimentos, com auxílio do Laboratório de Bioquímica e Microbiologia Aplicada, ambos do IBILCE/UNESP.

\subsection{Microrganismo}

Empregou-se a linhagem 425 do fungo entomopatogênico Metarhizium anisopliae, fornecida pelo Instituto Biológico de São Paulo. Antes do início dos experimentos, fezse um estoque da linhagem, em tubo de ensaio contendo meio batata-dextrose-ágar (BDA). No tubo, após o desenvolvimento do fungo, adicionou-se $1 \mathrm{~mL}$ de óleo mineral para formar uma camada protetora à colônia. $\mathrm{O}$ estoque foi mantido em freezer e utilizado para repicagem em todos os ensaios. A repicagem foi feita por picadas na superfície do meio de cultura BDA, utilizando-se um fio de níquelcromo.

Para utilização nos experimentos, foram efetuadas repicagens em erlenmeyer inclinados contendo $50 \mathrm{~mL}$ de BDA e incubados em câmara $\mathrm{DBO}$ à $28^{\circ} \mathrm{C}$ por 15 


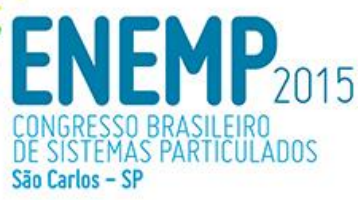

dias para desenvolvimento do fungo e sua esporulação.

Nos experimentos realizados com arroz tipo 1, quirera e farelo de arroz, o inoculo foi preparado adicionando-se solução de Tween 80 à $0,1 \%$. A superfície da colônia foi raspada com a ajuda da alça de Helen e recolhida a um frasco e a suspensão de esporos foi utilizada como inoculo.

\subsection{Testes Microbiológicos em embalagens plásticas de pequena dimensão}

Os ensaios fermentativos foram realizados em embalagens de polipropileno de $12 \mathrm{~cm}$ x $20 \mathrm{~cm}$ acopladas a um bocal de PVC de $3,6 \mathrm{~cm}$ de diâmetro, os quais foram tampados com tampão de algodão envolto por gaze, a fim de garantir a troca de gases e assegurar que não houvesse contaminação por outros microrganismos. Dentro de cada embalagem, foi colocado um arame na forma de espiral para facilitar a aeração e evitar a aglomeração do substrato. Uma embalagem empregada na fermentação pode ser vista na "Figura 1 - Embalagem de polipropileno pronta para a fermentação".

Figura 1 - Embalagem de polipropileno pronta para a fermentação.

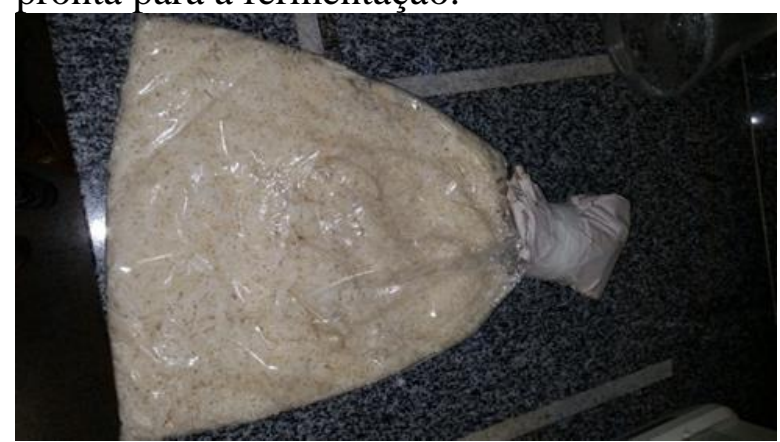

Fonte: Isabella C. Lopes (2015)

A temperatura de cultivo foi fixada em $28{ }^{\circ} \mathrm{C}$, definida por Pinto (2010) como ótima para o cultivo deste fungo. A granulometria do substrato foi empregando arroz tipo 1, e a umidade do substrato foi estabelecida adicionando-se água ao substrato seco.

Em cada saco plástico foram colocados $10 \mathrm{~g}$ de substrato seco, $7 \mathrm{~mL}$ de água destilada antes do processo de autoclavagem.

Após autoclavagem, foi inoculada a suspensão fúngica, na proporção de $1 \times 108$ esporos $/ \mathrm{mL}$ para cada embalagem e armazenados em câmara $\mathrm{DBO}$ à $28{ }^{\circ} \mathrm{C}$ em ausência de luz.

Ao final do processo, a extração dos conídios foi feita empregando-se solução Tween 80 à $0,1 \%$. Em cada embalagem foram adicionados $50 \mathrm{ml}$ de solução Tween 80, manipulando-se as embalagens manualmente para o desprendimento dos conídios. A contagem dos conídios foi feita em Câmara de Neubauer.

\subsubsection{Granulometria do substrato}

Nesse ensaio, comparou-se a produção de conídios em duas granulometrias do substrato. Para cada ensaio utilizou-se $10 \mathrm{~g}$ de substrato ao qual adicionou-se $7 \mathrm{~mL}$ de água destilada antes de autoclavar para os seguintes substratos: arroz do tipo 1 e quirera de arroz. Utilizou-se $0,5 \mathrm{~mL}$ de suspensão de inoculo na concentração de $1 \times 10^{8}$ conídios/mL para cada $10 \mathrm{~g}$ de substrato cru. O período de incubação foi realizado em câmara DBO à 28 ${ }^{\circ} \mathrm{C}$. Para cada tratamento foram realizadas três repetições independentes, com três réplicas cada tratamento.

\subsection{Ensaios de ampliação de escala em embalagens de polipropileno}

Como o processo de produção industrial de esporos de $M$. anisopliae normalmente é realizado em embalagens de polipropileno de $30 \mathrm{~cm}$ x $40 \mathrm{~cm}$ alojadas em prateleiras em salas climatizadas, buscou-se reproduzir este procedimento em laboratório. Para tanto, às embalagens foram acoplados bocais de PVC de $8 \mathrm{~cm}$ de diâmetro, os quais foram tampados com tampão de algodão envolto por 


\section{ENEMP \\ Th

gaze, a fim de garantir a troca de gases e assegurar que não houvesse contaminação por outros microrganismos. Dentro de cada saco fermentador, foram colocados dois arames na forma de espiral para facilitar a aeração e evitar a aglomeração do substrato, conforme pode ser visto na "Figura 2- Embalagens de polipropileno de maior dimensão".

Nestes ensaios foram empregados arroz tipo 1 com massa de $0,5 \mathrm{~kg}$, ao qual foi adicionado $350 \mathrm{~mL}$ de água destilada antes de autoclavar. Após autoclavagem e resfriamento, o substrato recebeu $25 \mathrm{~mL}$ de solução inoculo com 108 conídios/mL.

Figura 2 - Embalagens de polipropileno de maior dimensão

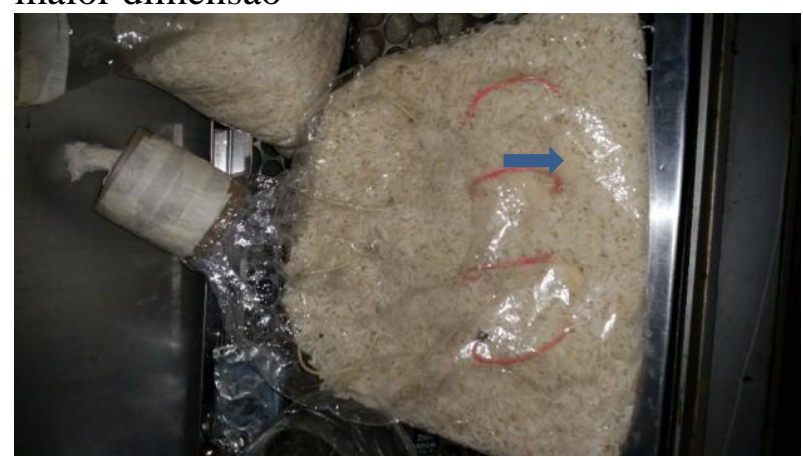

Fonte: Isabella C. Lopes (2015)

As embalagens ficaram acondicionadas em câmara $\mathrm{DBO}$ à $28{ }^{\circ} \mathrm{C}$ por 10 dias no escuro e, após este período, o material fermentado foi transferido para um recipiente maior, onde adicionou-se $2,5 \mathrm{~L}$ de solução Tween 80 à $0,1 \%$, sendo realizado a homogeneização manual para 0 desprendimento dos conídios. Desta suspensão foi retirada uma amostra para contagem dos conídios.

\subsection{Ensaios de ampliação de escala em biorreator de bandeja}

Um biorreator de bandeja foi elaborado em forma de caixa com gaveta para se realizar o processo de crescimento e fermentação do fungo Metarhizium anisopliae. A estrutura de funcionamento do biorreator de bandeja possui três conexões acopladas à gaveta para a entrada de ar, proveniente de um compressor radial de onde $\mathrm{o}$ ar, posteriormente enviado para um filtro cerâmico para retirada das impurezas e direcionado a um rotâmetro para o monitoramento e controle da vazão. Em seguida, o ar percola uma recheada com esferas de vidro e preenchido com água, instalada dentro da câmara DBO, de onde se ramifica em três tubulações para entrar no biorreator, também acondicionado na BOD como pode ser visto esquematicamente na "Figura 3 - Esquema do Biorreator de bandeja" e é apresentado em fotografia na "Figura 4 - Biorreator de bandeja".

Figura 3 - Esquema do Biorreator de bandeja

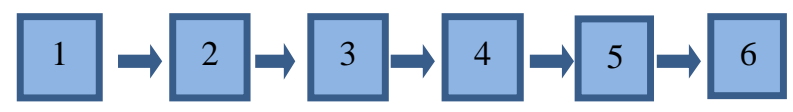

1- Compressor radial

2- $\quad$ Filtro cerâmico

3- Rotâmetro

4- Câmera BOD

5- $\quad$ Coluna de umidificação

6- Biorreator

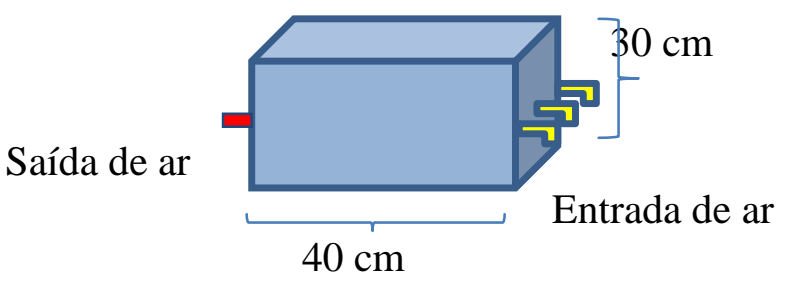

Fonte: Isabella C. Lopes (2015) 


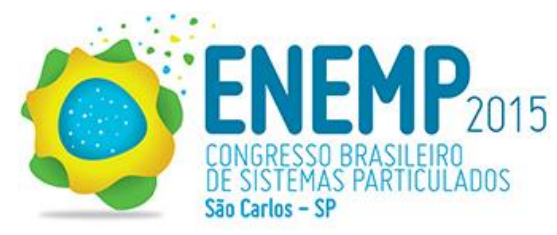

Figura 4 - Biorreator de bandeja

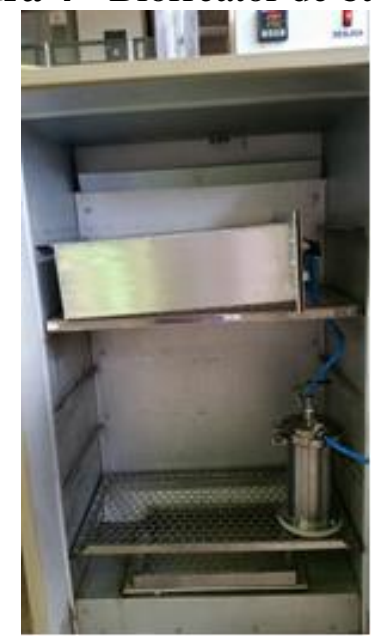

Fonte: Isabella C. Lopes (2015)

Para os testes no biorreator de bandeja, o substrato foi preparado em embalagem plástica utilizando-se os mesmos procedimentos de preparo do substrato e inoculo utilizados na embalagem plástica de maior dimensão, sendo que, a embalagem apenas foi vedada para autoclavagem. Após o processamento térmico, abriu-se uma pequena abertura na embalagem para receber a suspensão inoculo e realizar homogeneização do substrato e do inoculo, depositando-se a seguir o material inoculado dentro da caixa, a qual foi esterilizada previamente com álcool na concentração de $70 \%$ (v/v) e Lisoforme®.

Com o substrato inoculado e acondicionado dentro da caixa, preenchendo uma espessura de $2 \mathrm{~cm}$, totalizando $1 \mathrm{~kg}$, o biorreator foi colocado dentro da DBO à 28 ${ }^{\circ} \mathrm{C}$ por um período de 10 dias. Como a caixa não possui abertura, a fermentação ocorreu na ausência de luz.

Após o período de fermentação, adicionou-se 5 L de "solução Tween 80" dentro da própria caixa, sendo realizada homogeneização manual para o desprendimento dos conídios e desta suspensão foi retirada uma amostra para contagem dos conídios.

\section{RESULTADOS E DISCUSSÃO}

\section{$X X X V I I$ ENEMP \\ 18 a 21 de Outubro de 2015 \\ Universidade Federal de São Carlos}

$\mathrm{Na}$ "Tabela 1 - Produção de conídios em dois tipos de granulometria de substrato" são apresentados os resultados da produção de conídios para as duas granulometrias empregadas.

Tabela 1 - Produção de conídios em dois tipos de granulometria de substrato

\begin{tabular}{lcc}
\hline Substrato & Conídios/mL x 10 & $\begin{array}{l}\text { Aumento } \\
\text { relativo }\end{array}$ \\
\hline Arroz & $6,32 \pm 2,88$ & 24,0 \\
Quirera & $7,84 \pm 3,23$ & \\
\hline
\end{tabular}

Observa-se na "Tabela 4.1 - Produção de conídios em dois tipos de granulometria de substrato" que o uso da quirera resultou em maior produção de esporos com um aumento observado de $24 \%$. Tal aumento certamente está relacionado ao aumento da área superficial do substrato, uma vez que o diâmetro das partículas da quirera são menores às do arroz tipo 1 .

O preparo e manipulação dos dois tipos de substratos não apresentou nenhuma diferença ou dificuldade específica, mas devese levar em consideração o preço de mercado de cada tipo de substrato, uma vez que o arroz tipo 1 possui um preço de mercado superior, cerca de três vezes acima da quirera de arroz.

\subsection{Ampliação de escala em embalagens de polipropileno de maior dimensão}

Os testes em embalagem plástica de maior dimensão apresentaram uma redução de $80 \%$ na quantidade de conídios produzidos com relação à produção em escala reduzida no fotoperíodo de abrigo da luz, uma vez que foram produzidos $1,24 \times 10^{8}$ conídios $/ \mathrm{mL}$. Possivelmente o aumento na espessura da camada de substrato na embalagem dificultou a circulação de ar, fator determinante no crescimento satisfatório de Metarhizium anisopliae. 


\section{ENEMP \\ . EN \\ DE SISTEMAS PARTICULADOS \\ São Carlos - SP}

No ambiente industrial, as embalagens plásticas ficam abertas para permitir uma melhor aeração, desta forma, pode-se obter um resultado mais satisfatório com relação ao produzido em laboratório, mas a espessura do substrato na embalagem ocorre nos dois ambientes, fator este que diminui a produção de conídios por dificultar as trocas gasosas com o meio, acarretando em aumento de temperatura prejudicial ao fungo.

\subsection{Testes em Biorreator de bandeja}

Visualmente, não foi observado ressecamento da superfície do meio de cultivo, o que poderia ocorrer caso o ar não estivesse plenamente saturado na entrada do fermentador. O constante fluxo de ar permitiu a troca de gases e de calor produzido dentro do biorreator, proporcionando um crescimento uniforme em toda a espessura da camada de substrato a qual possuía $2 \mathrm{~cm}$ de espessura como mostra a "Figura 5 Fotografia da superfície do biorreator de bandeja após fermentação (a) e uniformidade das colônias na espessura do meio de cultivo (b).

Figura 5 - Fotografia da superfície do biorreator de bandeja após fermentação (a) e uniformidade das colônias na espessura do meio de cultivo (b).

a)

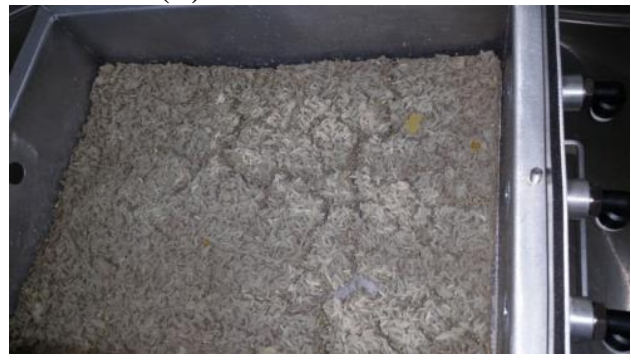

b)

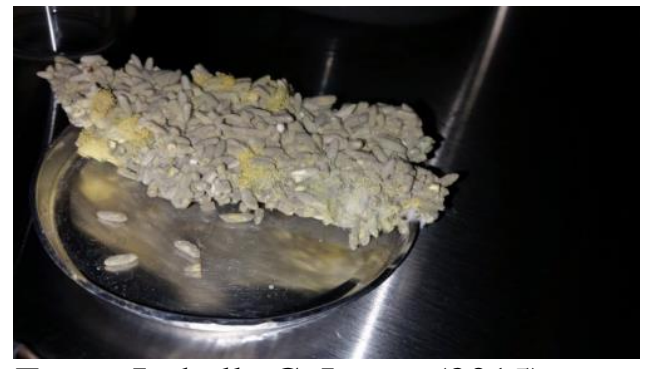

Fonte: Isabella C. Lopes (2015)

Os testes no biorreator foram comparados à produção em embalagem plástica como forma de se avaliar a eficiência de produção em biorreator, sendo que os testes foram realizados apenas com o substrato arroz cru, sendo os resultados obtidos no biorreator podem ser visualizados na "Tabela 2 Resultado obtido na fermentação nos três tipos de recipientes utilizados".

Tabela 2 - Resultado obtido na fermentação nos três tipos de recipientes utilizados

\begin{tabular}{cc}
\hline Recipiente & $\begin{array}{c}\text { Quantidade de } \\
\text { conídios } / \mathrm{mL}\end{array}$ \\
\hline $\begin{array}{c}\text { Embalagem plástica de } \\
\text { escala ampliada }\end{array}$ & $1,24 \times 10^{8}$ \\
$\begin{array}{c}\text { Embalagem plástica de } \\
\text { escala menor }\end{array}$ & $6,32 \times 10^{8}$ \\
Biorreator de bandeja & $4,64 \times 10^{8}$ \\
\hline
\end{tabular}

O biorreator de bandeja elaborado para os testes apresentou um bom desemprenho em termos de produtividade de conídios quando comparado com os resultados obtidos em embalagem plástica de maior dimensão e, de acordo com a estrutura elaborada, o biorreator permite o aumento na sua capacidade de produção, favorecido pela sua praticidade operacional e a exigência de pouco espaço físico para a sua acomodação, quesito este contrário a produção em embalagens plástica, que requer estrutura ampla para acomodação das embalagens em prateleiras.

\section{CONCLUSÕES}


$\mathrm{O}$ uso da quirela de arroz resultou em maior produção de conídios se comparado ao arroz cru devido a maior área superficial.

Em relação a produção em escala ampliada diminui, consideravelmente a produção de conídios.

E a utilização do biorreator de bandeja apresentou resultados consideráveis para uma produção em escala ampliada.

\section{REFERÊNCIAS}

ABDAESHAHIAN, P.; SAMAT, N.; HAMID, A. A.; YUSOFF, W. M. W. Utilization of palm kernel cake for production of $b \quad$ - mannanase by Aspergillus niger FTCC 5003 in solid state fermentation using an aerated column bioreactor. Journal of Industrial Microbiology and Biotechnology, 2010. v. 37, p. $103-109$.

ALMEIDA, J.E.M.; BATISTA FILHO, A.B. Microorganismos no controle de pragas. In: PINTO, A.S.; NAVA, D.E.; ROSSI, M.M.; MALERBO-SOUZA, D. T. Controle Biológico de pragas: na prática. Cap. 3, p.3544. Piracicaba: CP2, 2006.

ALTMAN, J; CAMPBELL, C. L. Effect of herbicides on plant diseases. Annual Review of Phytopathology, Palo Alto, v. 15, p. 361385, 1977.

ALVES, S.B. Fungos entomopatogênicos, p. 289-381. In: Alves, S.B. (Ed). Controle microbiano de insetos. Piracicaba: FEALQ, Piracicaba, 1163 p, 1998.

BEYS DA SILVA, W. O.; SANTI, L.; SCHRANK, A.; VAINSTEIN, M. H. Metarhizium anisopliae lipolytic activity plays a pivotal role in Rhipicephalus (Boophilus) microplus infection. Fungal Biology, Cambrigde, v. 114, p. 10-15, 2010.
CUNHA, D. C. da; SOUZA, J. A.; ROCHA, L. A. O.; COSTA, J. A. V. Hexahedral modular bioreactor for solid state bioprocesses. World Journal of Microbiology and Biotechnology, v. 25, p. 2173-2178, 2009.

FARIA, M. R.; WRAIGHT S. P. Mycoinsecticides and mycoacaricides: a comprehensive list with worldwide coverage and international classification of formulation types. Biological Control, Amsterdam, v.43, p. 237-256, 2007.

GHILDYAL, N. P. et al. Interaction of transport resistances with biochemical reaction in packed-bed solid-state fermentors: effect of temperature gradients. Enzyme Microb. Technol, n. 16, p. 253-257, 1994.

JENKINS, M. K., GARSIDE, P., INGULLI, E., MERICA, R.R., JOHSON, J.G., NOELLE, R.J. Visualization of Specific B and $\mathbf{T}$ Lymphocyte Interactions in the Lymph Node. Science 3 July 1998: Vol. 281 no. 5373 pp. 96-99.

LAURENTINO, C. L. Transferência de calor em leitos fixos com aplicação em reatores de fermentação em estado sólido. 2007. 105f. Dissertação (Mestrado), Universidade Estadual Paulista, São José do Rio Preto, 2007.

MATTSSON, J. L. Opinion: Improved food safety requires integration of pest, plant and pesticide interactions. Journal für Verbraucherschutz und Lebensmittelsicherheit, Berlin, v. 3, n. 8, p. 259-264, 2008.

MITCHELL, D. A. et al. New developments in solid-state fermentation. II. Rational 
approaches to the design, operation and scale up of bioreactors. Process Biochemistry, n. 35, p. 1211-1225, 2000.

MOCHI, D. A.; MONTEIRO, A. C.; BARBOSA, A. J. Action of pesticides to Metarhizium anisopliae in soil. Neotropical Entomology, Londrina, v. 34, n. 6, p. 961971, 2005.

OLIVEIRA, M. A. P.; MARQUES, E. J.; WANDERLEY-TEIXEIRA, V.; BARROS, R. Efeito de Beauveria bassiana (Bals.) Vuill. e Metarhizium anisopliae (Metsch.) Sorok. Sobre características biológicas de Diatraea saccharalis F. (Lepidoptera: Crambidae). Acta Scientiarum Biological Sciences, Maringá, v. 30, n. 2, p. 220-224, 2008.

PEREIRA, R.M., S.B. ALVES \& P.R. REIS. Segurança no emprego de entomopatógenos, p.21-38. In S.B. Alves, Controle microbiano de insetos, Piracicaba, Fealq, 2ed., 1163p, 1998.

PEREIRA, M. F. A.; BENEDETTI, R. A. L.; ALMEIDA, J. E. M. Eficiência de Metarhizium anisopliae (Metsch) Sorokin no controle de Deois flavopicta (Stal.,1854), em pastagem de capim (Brachiaria decombens). Arquivos do Instituto Biológico, São Paulo, v. 75, n. 4 , p. 465-469, 2008.

REFFSTRUP, T. K.; LARSEN, J. C.; MEYER, $O$. Risk assessment of mixtures of pesticides. Current approaches and future strategies. Regulatory Toxicology and Pharmacology, New York, v. 56, p. 174-192, 2010.

ROBERTS, D. W.; ST LEGER, R. J. Metarhizium spp., cosmopolitan insectpathogenic fungi: mycological aspects. Advances in Applied Microbiology, New York, v. 54, p. 1-70, 2004.
ST LEGER, R. J.; COOPER, R. M.; CHARNLEY, A. K. Characterization of chitinase and chitobiase produced by the entomopathogenic fungus Metarhizium anisopliae. Journal of Invertebrate Pathology, San Diego, v. 58, p. 415-426, 1991.

ST LEGER, R. J.; DURRANDS, P. K.; CHARNLEY, A. K.; COOPER, R. M. Role of extracellular chymoelastase in the virulence of Metarhizium anisopliae for Manduca sexta. Journal of Invertebrate Pathology, San Diego, v. 52, p. 285-293, 1988.

TONUS, M. Manejo integrado controla cigarrinhas em pastagens. Revista Balde Branco, São Paulo, n. 421, 1999.

VIRTANEN, V.; NYYSSOLA, A.; VUOLANTO, A.; LEISOLA, M.; SEISKARI, P. Bioreactor for solid state cultivation of Phlebiopsis gigantea. Biotechnological Letters, v. 30, p. $253-258$, 2008a.

ZHAO, S. Cost-effective production of Bascillus licheniformis using simple netting bag solid bioreactor. World Journal of Microbiology and Biotechnology, v. 24, p. 2859 - 2863, 2008. 